\title{
VERIFYING THE OPERATIONAL DEFINITION OF NEIGHBORHOOD FOR THE PSYCHOSOCIAL IMPACT OF STRUCTURAL DETERIORATION
}

\author{
Daniel J. Kruger \\ University of Michigan
}

The physical decay of neighborhoods is associated with social conditions such as disease risk, poor mental health, and fear of crime. Researchers assessing neighborhood effects commonly operationalize neighborhoods via municipal boundaries such as U.S. Census Tracts, although more sophisticated analyses examine structures within a defined radius of respondents, typically .25 mile. This study verifies the .25 -mile heuristic as a sound operational definition for neighborhood residential structures consequential to social conditions with measures of social contact with neighbors, perceptions of social capital, fear of neighborhood crime, and satisfaction with neighborhood quality of life. Deteriorating commercial structures cluster in smaller areas than deteriorating residential structures; however, the peak consequential radius appears to occur at 4 times the distance of residential structures. (c) 2007 Wiley Periodicals, Inc.

The physical decay of neighborhoods is associated with social conditions such as disease risk, poor mental health, and fear of crime (Cohen, Spear, Scribner, Kissinger, Mason, \& Wildgen, 2000; Perkins \& Taylor, 1996). In fact, the "Chicago School" of Sociology strongly emphasized the impact of neighborhood physical decay on health problems (Faris \& Dunham, 1939; Park \& Burgess, 1925). One study found that a neighborhood index measuring housing quality, abandoned cars, graffiti, trash, and public school deterioration explained more of the variance in gonorrhea rates than did

The 2003 Speak to Your Health! Community Survey was supported by the Prevention Research Center (PRC) of Michigan (Centers for Disease Control and Prevention Grant No. U48/CCU515775) and the Genesee County Health Department. I would like to thank the PRC Survey Committee members and all those who participated in the project.

Correspondence to: Daniel J. Kruger, School of Public Health, University of Michigan, 1420 Washington Heights, Ann Arbor, MI 48109-2029. E-mail: djk2012@gmail.com 
a poverty index measuring income, unemployment, and low education (Cohen et al., 2000).

There are several theoretical models depicting how neighborhood conditions could affect mental health (Wandersman \& Nation, 1998). The environmental stress model connects aspects of the physical environment and individual mental health outcomes, as mediated by successful and unsuccessful coping (Baum, Singer, \& Baum, 1981; Wandersman, Andrews, Riddle, \& Fawcett, 1983). The neighborhood disorder model suggests that social incivilities (e.g., public drunkenness, street harassment) and physical incivilities (e.g., abandoned buildings, dilapidated housing) affect crime rates and fear of crime. Fear of crime could, in turn, impact residents' mental health (Wandersman \& Nation, 1998; White, Kasl, Zahner, \& Will, 1987).

Collective efficacy theory states that mutual trust and solidarity among neighborhood residents mediates the relationship between neighborhood factors and residents' well-being (Sampson, Raudenbush, \& Earls, 1997). Relations with neighbors and social support from interactions with neighbors are strongly related to the subjective sense of community (Prezza, Amici, Roberti, \& Tedeschi, 2001). Support from good social networks is related to lower levels of child abuse, even in neighborhoods with high concentrated poverty (Garbarino \& Kostelny, 1992).

Interpersonal trust among community members is part of the core definition of social capital (Coleman, 1990; Putnam, 1993). Greater trust of neighbors is related to lower rates of homicide, assault, robbery, and burglary (Kawachi, Kennedy, \& Wilkinson, 1999). Neighborhood social capital could impact health directly and also as mediated through local rates of crime (Kawachi, Kennedy, \& Wilkinson, 1999). Socially disorganized communities are characterized by depleted social capital, which has been repeatedly shown to be related to greater levels of crime (Sampson, 1995). Deteriorating neighborhood structures might also be associated with concerns over safety (Austin, Furr, \& Spine, 2002) because these physical cues may be seen as an indicator of a lack of social control (Ross \& Mirowsky, 1999).

Guided by these theoretical models, research on neighborhood effects has assessed the relationships between physical conditions and perceptions of social conditions. Living in deteriorating neighborhoods may have both direct and indirect effects on the experience of stress. An individual in a deteriorating neighborhood may directly experience the stress associated with living in a residence needing repairs, exposing the individual to extreme temperatures, damaged appliances and fixtures (e.g., lighting, plumbing), and to potentially dangerous conditions such as exposed nails or peeling paint. If the individual lives near deteriorating buildings, the indirect effects could include the strain of living in a neighborhood with declining home values, crime fears associated with living near abandoned or damaged properties, and the strain of living near property with high resident turnover that often occurs in economically depressed neighborhoods.

There are currently many operational definitions of neighborhood in this area of research, including the block, Census Tract, and ZIP code levels. These municipal and political definitions are conducive to hierarchical linear modeling. However, the Census Tract is a rather large unit of analysis; it often contains several distinct neighborhoods and is not necessarily representative of neighborhood boundaries (Farrell, Aubry, \& Coulombe, 2004). The heterogeneity of Census Tracts may present problems for analysis of neighborhood effects, smaller homogeneous neighborhoods defined by specific criteria may be more useful (Wiesenfeld, 1996). Area definitions at the ZIP code level, being much larger than Census Tracts, exacerbate these problems. 
Geographical information systems (GIS) allow researchers to define their own geographic units of analysis. The "rule of thumb" for examining effects of the built environment is a radius distance of .25 mile from the residence of the respondent (Institute of Medicine Transportation Research Board, 2005) which is based on a Bayesian model of critical acceptable pedestrian walking distances (Seneviratne, 1985).

The current project empirically verifies the appropriateness of the standard radius operational definition of neighborhood, by determining the geographic unit of neighborhood physical conditions that most closely corresponds with perceptions of community conditions. Both the direct and indirect effects of living in deteriorating neighborhoods are likely to be mediated by the cognitive appraisal of neighborhood conditions (Lazarus, 1999; Sandler, Wolchik, MacKinnon, Ayers, \& Roosa, 1997). The current study assesses the relationships between physical deterioration of neighborhood structures and constructs with demonstrated relationships to physical and mental health outcomes: neighborhood social contact, neighborhood social capital, satisfaction of neighborhood quality of life, and fear of neighborhood crime. Deterioration of nonresidential properties has been found to have a greater impact on fear of crime than deterioration of residential properties (Perkins \& Taylor, 1996). Thus, data for commercial and residential properties were analyzed separately. In addition, the spatial patterns of commercial structures differ from residential structures, as they are clustered along a subset of streets with commercial zoning. Many residents may live more than .25 mile from any commercial structures, but still take them into consideration when assessing neighborhood conditions.

\section{METHOD}

The Prevention Research Center of Michigan's (PRC/MI) Speak to Your Health! Community Survey was developed through a collaborative process by a survey committee composed of members from the University of Michigan's School of Public Health, the Genesee County Health Department, the Greater Flint Health Coalition, University of Michigan-Flint, the Genesee County Community Action Resource Department, and the Flint Odyssey House Health Awareness Center. The survey was designed to monitor and understand community health and community concerns, monitor the impact of PRC/MI and other health initiatives on community health outcomes, and promote change that improves the health of Genesee County communities. The survey project was approved by the University of Michigan's Institutional Review Board and by a committee composed of community representatives.

\section{Sample}

Random samples of households were drawn from Genesee County Census Tracts; at least 20 residents were obtained for each of the 39 residential Census Tracts in the city of Flint and at least 10 from each of the 90 Census Tracts outside of Flint. Telephone interviews were conducted from January to April of 2003. The response rate was $15 \%$.

Our analyses utilized data from 801 respondents in Flint, missing values (3\%) were imputed using the linear trend predictions from other variables in the analysis. Of these respondents, $69 \%$ were women, $38 \%$ were married, $57 \%$ were African American, $43 \%$ were White, and $18 \%$ were unemployed. Education attainments of respondents 25 years and older were 12\% less than high school, 33\% high school graduate, $32 \%$ technical school or some college, $10 \%$ associates degree, $8 \%$ bachelor's degree, and $5 \%$ 
master's degree or higher. Respondents' ages ranged from 18 to 100 years, with a median of $45(M=45, S D=15)$. In 2000, the population of Flint was $53 \%$ female, $53 \%$ African American, 41\% White, and the median age was 31 (U.S. Census, 2001a). Education attainments of residents 25 years and older were $25 \%$ less than high school, $32 \%$ high school graduate, $24 \%$ technical school or some college, $6 \%$ associates degree, $7 \%$ bachelor's degree, and 4\% master's degree or higher (U.S. Census, 2001b).

\section{Measures}

Neighborhood social capital was assessed with two items used in previous studies (Ellen, Jennings, Meyers, Chung, \& Taylor, 2004; Sampson et al., 1997); respondents indicated the degree to which people in their neighborhood could be trusted and were willing to help their neighbors (Cronbach's $\alpha=.764$ ). Respondents' satisfaction with the quality of life in their neighborhood and degree of social contact with their neighbors were each assessed with one previously used item (Sampson et al., 1997). Perceptions of neighborhood crime and safety were assessed with a 4-item scale (Smith, Steadman, Minton, \& Townsend, 1999); the items were "How fearful are you about crime in your neighborhood?," "How safe is it to walk around alone in your neighborhood during the daytime?," "How safe is it to walk around alone in your neighborhood after dark?," and "Compared to other neighborhoods, the crime rate in my neighborhood is... (Very High to Very Low)." This scale had a Cronbach's $\alpha$ of .831.

Data on neighborhood physical conditions in Flint were obtained from the Flint Environmental Block Assessment (EBA) Web site (For description, methods, and materials, see http://flinteba.org). The original EBA was developed in the late 1960s by the American Public Health Association to assess housing quality by conducting a "sidewalk" survey and evaluation of a community's housing stock. The current EBA project was conducted by researchers at the University of Michigan-Flint and assessed all of nearly 60,000 real estate parcels located within Flint in 2000. Urban planning and geographic information systems consultants from the University of Michigan's Ann Arbor campus and community advisors developed assessment tools for neighborhood structures. Each parcel was rated on a scale from 0 to 25 based on the condition of the building foundation, exterior surfaces, stairs, rails, porches, roofs, gutters, downspouts, chimneys, windows, doors, and landscaping. Ratings were conducted by 55 trained field assessment workers. All residential and commercial structures that were rated as being in major disrepair (scores from 5-9, $1 \%$ of residential, $16 \%$ of commercial) and not salvageable (scores from $0-4,0.2 \%$ of residential, $1.8 \%$ of commercial) were selected. Interrater reliabilities (Cronbach's $\alpha$ ) for total scores were .703 for residential structures and .942 for commercial structures.

Geographical information systems located the addresses of survey respondents and selected residential and commercial structures on a map of Flint. Data were split into six areas separated by natural edges, such as the Flint River and limited access highways. The distances at which spatial autocorrelations were maximized for residential and commercial structures were assessed. The numbers of residential structures classified as being in major disrepair or not salvageable within each area for different radii of respondents ranging from .05 mile to 1 mile and commercial structures ranging from .05 mile to 2 miles were correlated with perceptions of neighborhood social conditions.

To compare the utility of GIS specified neighborhood areas with municipal definitions, counts of residential and commercial structures that were rated as being in 
major disrepair and not salvageable were computed by Census Tract and ZIP code. The appropriate count was added to the data for each survey respondent. The correlation between these counts and the four outcome measures were calculated.

\section{RESULTS}

The spatial autocorrelation, or clustering, of dilapidated residential structures reached a maximum at .45 mile (Moran's Index $=0.0215, Z$-score of standard deviations $=2.53)$. Spatial autocorrelation of dilapidated commercial structures reached a maximum at .175 mile (Moran's Index $=0.1400, Z$-score of standard deviations $=3.7$ ).

The conditions of residential and commercial structures were directly related to fear of neighborhood crime and inversely related to social contact with neighbors, perceptions of social capital, and satisfaction with neighborhood quality of life. The relationship between condition of residential structures and perceptions of neighborhood conditions was highest between .20 and .35 mile, although the correspondence with social contact with neighbors peaked at an assessment radius of .75 miles (see Figure 1). The relationship between condition of commercial structures and perceptions of social capital and fear of neighborhood crime peaked at a radius of 1.05 miles (see Figure 2), although the correspondences with satisfaction with neighborhood quality of life and social contact with neighbors peaked at respective radii of .85 and 1.65 miles.

Seven of eight indicators demonstrated higher correspondence with GIS-specified neighborhood areas than with municipal definitions (see Table 1). Neighborhood satisfaction demonstrated a higher correspondence to the concentration of dilapidated residential structures as defined by Census Tract $(r=.137)$ than to the .25 -mile radius $(r=.100$; peaking at $r=.115$ at .35 miles $)$ or ZIP code $(r=.034)$ areas. For the concentration of dilapidated residential structures, the average correlations were .136 , .117 , and .040 for the .25-mile radius, Census Tract, and ZIP code areas respectively. For the concentration of dilapidated commercial structures, the average correlations were .109, .021, and .048 for the one-mile radius, Census Tract, and ZIP code areas, respectively.

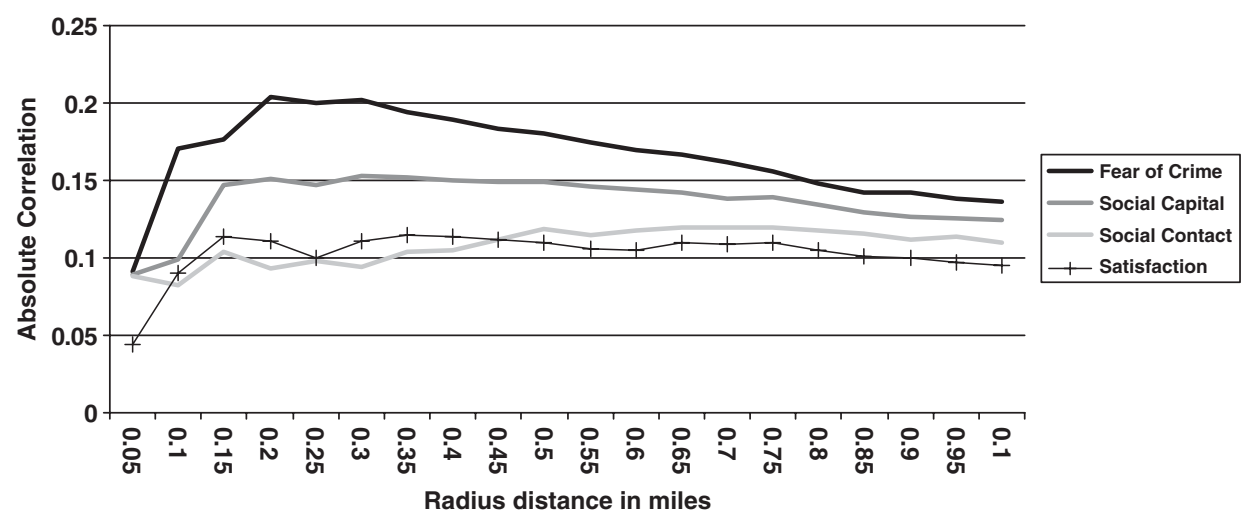

Figure 1. Radius for assessing deteriorated residential structures and perceptions of community conditions. 


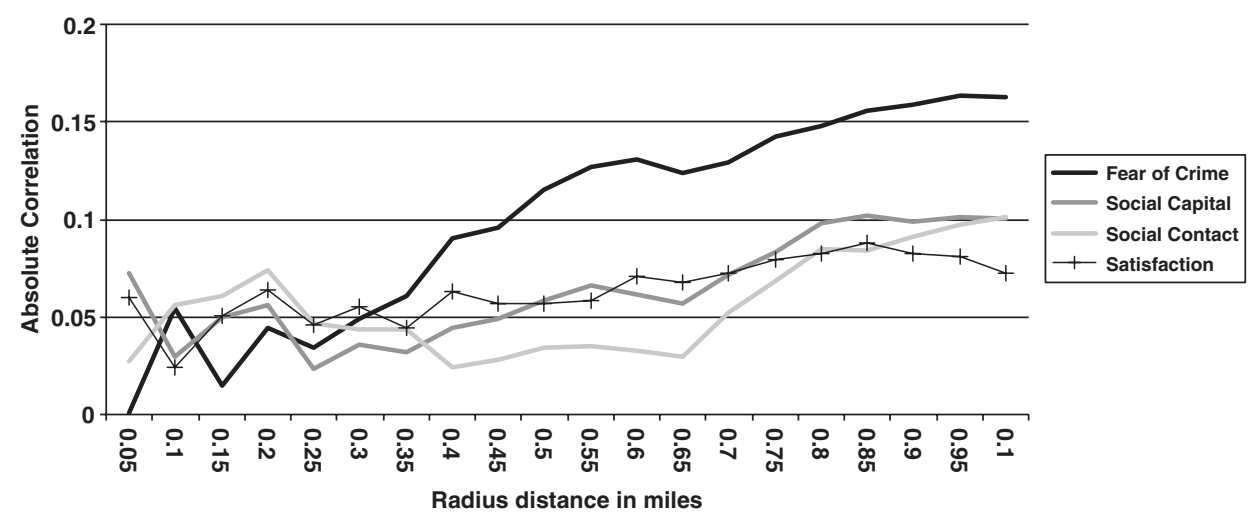

Figure 2. Radius for assessing deteriorated commercial structures and perceptions of community conditions.

Table 1. Correlation Coefficients by Construct and Neighborhood Definition

\begin{tabular}{lccccccr}
\hline & \multicolumn{3}{c}{ Residential structures } & & \multicolumn{2}{c}{ Commercial structures } \\
\cline { 2 - 3 } Construct & .25 Mi radius & Tract & ZIP & & 1 Mi radius & Tract & ZIP \\
\hline Fear of crime & .200 & .140 & .048 & .162 & .025 & .034 \\
Social capital & .147 & .119 & .036 & .100 & .020 & .097 \\
Social contact & .098 & .071 & .041 & & .101 & .021 & .012 \\
Satisfaction & .100 & .137 & .034 & .073 & .018 & .047 \\
\hline
\end{tabular}

Note. Correlation coefficients are presented as absolute values.

\section{DISCUSSION}

The common .25-mile radius operational definition for neighborhood is appropriate for assessing the impact of the condition of residential, but not commercial, structures on resident perceptions of neighborhood social conditions. Results generally validated the .25-mile heuristic for assessing the physical conditions of residential structures. Associations with perceptions of neighborhood social capital, fear of neighborhood crime, and satisfaction with neighborhood quality of life were strongest with measurement criteria close to this radius. Social contact with neighbors appears to be related to a broader geographical range of residential structures. In contrast, associations between the physical deterioration of commercial structures and perceptions of neighborhood social conditions were relatively weaker with a .25-mile assessment radius and peaked with a radius from 3 to 6 times this distance. The GISspecified neighborhood areas were generally more powerful predictors of neighborhood social perceptions than Census Tracts or ZIP codes, especially so for the deterioration of commercial structures.

Thus, results suggest that researchers should distinguish between residential and commercial structures and should use a broader radius of analysis for the impact of commercial structures on neighborhood residents. These results also indicate that the specific constructs under examination may vary in terms of the geographical scope 
considered in judgments. However, this pattern could also be due to the measurement properties of multiitem versus single-item indicators. Due to time constraints on survey telephone interviews, two of the indicators used were single-item measures. This may result in lower reliability, and results suggested that strength of associations would be improved with multiitem scales. These results may not generalize to areas with substantially higher or lower building density. Flint is a mid-size city characterized by moderately dense neighborhoods of single-family homes, with a small proportion of multiunit dwellings. There are very few high-rise residential structures in the city.

It is noted that the physical clustering of dilapidated residences in the city under study appears to have a broader geographical range than the empirically inferred range of a resident's practically significant neighborhood. Deteriorating commercial structures have a much smaller area of clustering than residential structures, although the psychological impact of these deteriorating commercial structures appears to have a wider range than that for residential structures.

Community researchers and providers of psychological services would be wise to consider the impact of neighborhood conditions on physical and mental health. Legislators and public officials should also be aware of the negative social and health consequences of neighborhood physical deterioration. In recent years, Land Banks have been created to revitalize delinquent properties. These and other efforts of neighborhood reconstruction and beautification may have a broad impact in improving the quality of life for neighborhood residents.

\section{REFERENGES}

Austin, M.D., Furr, L.A., \& Spine, M. (2002). The effects of neighborhood conditions on perceptions of safety. Journal of Criminal Justice, 30, 417-427.

Baum, A., Singer, J.E., \& Baum, C.S. (1981). Stress and the environment. Journal of Social Issues, 37, 4-35.

Cohen, D., Spear, S., Scribner, R., Kissinger, P., Mason, K., \& Wildgen, J. (2000). "Broken windows" and the risk of gonorrhea. American Journal of Public Health, 90, 230-236.

Coleman, J.S. (1990). Foundations of social theory. Cambridge, MA: Harvard University Press.

Ellen, J.M., Jennings, J.M., Meyers, T., Chung, S., \& Taylor, R. (2004). Perceived social cohesion and prevalence of sexually transmitted diseases. Sexually Transmitted Diseases, 31, 117-122.

Faris, R., \& Dunham, H.W. (1939). Mental disorders in urban areas. Chicago: University of Chicago Press.

Farrell, S.J., Aubry, T., \& Coulombe, T.A. (2004). Neighborhoods and neighbors: Do they contribute to personal well-being. Journal of Community Psychology, 32, 9-25.

Garbarino, J., \& Kostelny, K. (1992). Child maltreatment as a community problem. Child Abuse and Neglect, 16, 455-464.

Institute of Medicine Transportation Research Board. (2005). Does the built environment influence physical activity? Examining the evidence (TRB Special Report 282). Washington, DC: Author.

Kawachi, I., Kennedy, B.P., \& Wilkinson, R.G. (1999). Crime: Social disorganization and relative deprivation. Social Science \& Medicine, 48, 719-731.

Lazarus, R.S. (1999). Stress and emotion: A new synthesis. New York: Springer.

Park, R.E., \& Burgess, E.W. (1925). The city. Chicago: University of Chicago Press.

Perkins, D.G., \& Taylor, R.B. (1996). Ecological assessments of community disorder: Their relationship to fear of crime and theoretical implications. American Journal of Community Psychology, 24, 63-107. 
Prezza, M., Amici, M., Roberti, T., \& Tedeschi, G. (2001). Sense of community referred to the whole town: Its relations with neighboring, loneliness, life satisfaction and area of residence. Journal of Community Psychology, 29, 29-52.

Putnam, R.D. (1993). Making democracy work. Civic traditions in modern Italy. Princeton: Princeton University Press.

Ross, C.E., \& Mirowsky, J. (1999). Establishing a sense of personal control in the transition to adulthood. Social Forces, 77, 1573-1599.

Ross, C.E. (2000). Neighborhood disadvantage and adult depression. Journal of Health and Social Behavior, 41,177-187.

Sampson, R.J. (1995). The community. In J.Q. Wilson \& J. Petersilia (Eds.), Crime (pp. 193-216). San Francisco, CA: Institute for Contemporary Studies.

Sampson, R.J., Raudenbush, S.W., \& Earls, F. (1997). Neighborhoods and violent crime: A multilevel study of collective efficacy. Science, 227, 918-923.

Sandler, I.N., Wolchik, S.A., MacKinnon, D., Ayers, T.S., \& Roosa, M.W. (1997). Developing linkages between theory and intervention in stress and coping processes. In S.A. Wolchik \& I.N. Sandler (Eds.), Handbook of children's coping: Linking theory and intervention (pp. 3-41). New York: Plenum.

Seneviratne, P.N. (1985). Acceptable walking distances in central areas. Journal of Transportation Engineering, 3, 365-376.

Smith, S.K., Steadman, G.W., Minton, T.D., \& Townsend, M. (1999). Criminal victimization and perceptions of community safety in 12 cities, 1998. Washington, DC: Bureau of Justice Statistics and Office of Community Oriented Policing Services, U.S. Department of Justice. Retrieved from http://www.ojp.usdoj.gov/bjs/pub/pdf/cvpcs98.pdf

U.S. Census. (2001a). Census 2000 Summary File 1. Washington, DC: Author. Retrieved July 27, 2006, from http://factfinder.census.gov/

U.S. Census. (2001b). Census 2000 Summary File 3. Washington, DC: Author. Retrieved July 27, 2006, from http://factfinder.census.gov/

Wandersman, A., Andrews, A.B., Riddle, D., \& Fawcett, C. (1983). Environmental psychology and prevention. In R.D. Felner, L.A. Jason, J.N. Moritsugu, \& S.S. Farber (Eds.), Preventive psychology: Theory, research and practice (pp. 104-127). Elmsford, NY: Pergamon Press.

Wandersman, A., \& Nation, M. (1998). Psychological contributions to understanding toxicity, resilience, and interventions. American Psychologist, 53, 647-656.

White, M., Kasl, S.V., Zahner, G.E.P., \& Will, J.C. (1987). Perceived crime in the neighborhood and mental health of women and children. Environment and Behavior, 19, 588-613.

Wiesenfeld, E. (1996). The concept of "we": A community social psychology myth? Journal of Community Psychology, 24, 337-345. 